\title{
REVALORACIÓN DE LA CONSTITUCIÓN ORIGINAL DE 1917, EN LA ERA DE LA CUARTA TRANSFORMACIÓN MEXICANA, Y LOS CONCEPTOS DE CONSTITUCIÓN POLÍTICA, GEOGRÁFICA Y MORAL
}

\author{
Francisco José de ANDREA SÁNCHEZ*
}

\begin{abstract}
Sumario: I. Contexto general. II. Consideraciones generales. III. Reconsideración de los conceptos de constitución geográfica-demográfica y moral, y Constitución politica en la historia mexicana. IV. El diseño constitucional original de la Constitución de 1917 y su contenido esencial: el original sistema presidencial, el principio de sufragio efectivo y no reelección, y el articulado social. V. Los factores geopolíticos mundiales que vulneran la soberanía política, jurídica y financiera de la nación mexicana, vía las propuestas de contrarreforma de los tres pilares del constitucionalismo nacionalista y social de 1917. VI. Consideraciones finales.
\end{abstract}

\section{Contexto General}

A finales de 2018 parece estar de moda hablar del vocablo "Constitución" no sólo en referencia la Constitución Política mexicana de 1917, sino ahora también a una "constitución moral". Pero adicionalmente, y ya desde el siglo pasado, un importante historiador del derecho, Toribio Esquivel Obregón, destacó en una obra injustamente olvidada Prolegómenos a la historia

\footnotetext{
* Investigador en el Instituto de Investigaciones Jurídicas en la UNAM.
} 
constitucional, ${ }^{1}$ importantes consideraciones plenamente vigentes sobre la naturaleza de lo que él califica como la constitución propiamente "geográfica" que tienen todos los países del mundo como un tema relevante en el estudio, análisis e interpretación de la Constitución propiamente política. Esquivel señala que así como las personas tienen una constitución física ${ }^{2}$ según sus características personales, las naciones también tienen una constitución geográfica, étnica, mental y hasta psicológica que determina el comportamiento colectivo de las sociedades que componen los Estados contemporáneos a través de sus historias específicas y que, por ende, constituye un error ignorar estos datos constitutivos de la idiosincrasia nacional al diseñar una Constitución propiamente "política" que regirá la dinámica jurídica, política, electoral, económica y financiera de un país.

Las anteriores ideas de Toribio Esquivel - en apariencia tan sencillas y llenas de sentido común - son ignoradas con gran frecuencia por los legisladores, constituyentes y por las propias sociedades que con frecuencia incorporan instituciones, figuras y proyectos de nación en sus Constituciones políticas que resultan ajenas a la constitución geográfica, étnica e incluso moral de sus respectivos países.

En el anterior sentido, por ejemplo, para ilustrar la importancia de las observaciones hechas arriba, basta un breve recorrido por la historia parlamentaria inglesa que nos ilustra acerca de cómo el sistema político y constitucional británico está íntimamente ligado a la constitución étnica, psicológica y geográfica del Reino Unido; así como también, en el caso de los Estados Unidos de América, su célebre constitución paradigmática, con la creación de la institución presidencial moderna por antonomasia, e imitada en algunos de sus aspectos por las leyes fundamentales mexicanas, también proviene directamente de la experiencia propiamente estadounidense, desde el origen de los Estados Unidos en su etapa de las 13 colonias originales. ${ }^{3}$

Para México, y éste sería el objetivo general de este ensayo, la esencia nacional, cultural, étnica, psicológica e incluso geográfica también se ha reflejado en los principales textos constitucionales mexicanos, y de manera muy poderosa en la Constitución Política de 1917 original, que es de manera generalizada considerada por el derecho comparado como un texto constitucional social pionero en los ámbitos laboral, agrario, y con un contenido

1 Esquivel Obregón, Toribio, Prolegómenos a la historia constitucional de México, México, UNAM, 1980, p. 13, disponible en https://biblio.juridicas.unam.mx/bjv/detalle-li bro/692-prolegomenos-a-la-historia-constitucional-de-mexico.

2 Ibidem, pp. 13 y 14.

3 Idem. 
de proyecto de nación ciertamente encomiable, que no ha terminado de adquirir forma plena en los últimos 100 años; por lo cual merece una revaloración, pues éste sería de manera subconsciente e indirecta el deseo profundo de la mayoría de la población mexicana contemporánea, que el 1 de julio de 2018 mostró un rechazo a modelos fallidos y un deseo de revalorar los pilares políticos económicos y étnicos que fundamentan la idiosincrasia mexicana, y que quizá fueron corporizados de manera casi ideal en algunos rubros de la Constitución original de 1917.

Ahora bien, existe por supuesto la corriente de opinión especializada que señala la imposibilidad — avanzado el siglo XXI - de regresar al pasado bajo un contexto nacional e internacional dramáticamente distinto a los existentes a principios del siglo XX. Sin duda, la globalización y los avances tecnológicos han complejizado la vida en sociedad en todas las naciones contemporáneas, surgiendo en todos los países fenómenos culturales, jurídicos y políticos inexistentes hace 100 años. Sin embargo, cabe señalar que si bien México se inserta actualmente entre las 12 economías más poderosas del mundo en términos de medición del producto nacional bruto y tiene el potencial de ubicarse entre las primeras cinco en las próximas décadas, ${ }^{4}$ la distribución de la riqueza - ese sempiterno gran problema nacional- sigue tan vigente en 2018 como lo estuvo a principios del siglo XX cuando se diseñó el texto original de la ley fundamental de 1917.

Por otro lado, el presidente constitucional de México, Andrés Manuel López Obrador (AMLO), ante la devastación social y moral evidente en México en 2018, repetidamente ha hecho referencia a un tercer tipo de constitución: la "constitución moral", inspirándose en otro intelectual mexicano - Alfonso Reyes - del siglo pasado, relativamente relegado a la oscuridad por la generación del milenio, cuyo prestigio nacional e internacional llevaron al autor argentino Jorge Luis Borges a declarar públicamente que era uno de los escritores e intelectuales que más admiraba en el mundo por su erudición y excelencia literaria del más alto nivel.

4 Andrea Sánchez, Francisco J. de, La selección de candidatos politicos y las plataformas electorales: una guía para entender las elecciones presidenciales de Estados Unidos en 2016 y de México en 2018, México, UNAM, 2018, p. 6, disponible en https://biblio.juri dicas.unam.mx/bjv/detalle-libro/4859-la-seleccion-de-candidatos-politicos-y-las-platafor mas-electorales-una-guia-para-entender-las-elecciones-presidenciales-de-eua-en-2016-yde-mexico-en-2018. 
"El escritor argentino admiraba la prosa de Reyes, la cual calificaba como un instrumento elegante y preciso". ${ }^{5}$ En este sentido, no debe causar sorpresa que López Obrador haya encontrado inspiración en Reyes para proponer la elaboración de una constitución "moral” mexicana. Así, "en específico, López Obrador se basó en La Cartilla Moral, conciencia del entorno, un ensayo que escribió Reyes en 1944 a solicitud de Jaime Torres Bodet, entonces Secretario de Educación Pública". 6

Cabe destacar que Torres Bodet, otro distinguido intelectual y funcionario del siglo pasado, enfrascado de lleno en la labor de construir un sistema educativo acorde a la idiosincrasia nacional, se apoyó en la cartilla de Alfonso Reyes, que "tenía la intención de ser una base para la alfabetización en México, que sintetiza 6 respetos de la moral":

1. "El respeto a nuestra persona en cuerpo y alma".

2. "El respeto a la familia".

3. "El respeto a la sociedad humana en general y a la sociedad particular en que nos toca vivir".

4. "El respeto a la patria".

5. "El respeto a la especie humana".

6. "El respeto a la naturaleza".

Cabe resaltar también, como respuesta útil a los detractores de la idea de López Obrador respecto a la propuesta de una "constitución moral”, que el propio Alfonso Reyes escribió que "la moral es como una Constitución no escrita, cuyos preceptos son de validez universal para todos los pueblos y para todos los hombres". ${ }^{7}$

Así pues, otro de los objetivos principales de este estudio es resaltar como en 2018 - al inicio de la cuarta transformación - parecen haberse alineado los tres tipos de constitución referidos en una coincidencia, quizá no tan fortuita, y que como veremos adquiere relevancia por el impacto que tendrá el tema en la vida nacional.

5 Gómez, Jorge Eduardo, "El imaginario de la literatura mexicana que cautivó a Borges", Expansión, México, 1 de agosto de 2012, disponible en https://expansion.mx/entre tenimiento/2012/08/01/maria-kodama-explica-la-relacion-de-borges-con-mexico-a-travesdel-aleph.

6 Editor_Pxp, “QQué es la Constitución Moral de AMLO?”, Diario Digital Punto por Punto, México, 26 de noviembre de 2018, disponible en https://www.puntoporpunto.com/ secciones/politica-en-punto/que-es-la-constitucion-moral-de-amlo/.

7 Idem. 
Por otro lado, nuestro rescate del "baúl de los olvidos" de las ideas de Esquivel Obregón, en conjunción con el rescate de AMLO de las ideas de Reyes, obedecen a que son una herramienta útil para entender el porqué del regreso, no sólo nostálgico sino muy real, al espíritu original del texto de la Constitución de 1917, pues como los diseñadores posteriores de la ley fundamental quizá han extraviado o perdido el rumbo, errando en muchas reformas constitucionales recientes, han convertido a la Constitución de 1917 en un verdadero "Frankenstein" jurídico-constitucional mexicano.

Por lo anterior, los conceptos de constitución geográfica, étnica y psicológica, y los de constitución moral, nos pueden ayudar a diagnosticar qué labor de restauración e ingeniería jurídica constitucional es necesaria para "acoplar" adecuadamente la Constitución política mexicana a la constitución geográfica, étnica, psicológica y moral de las esencias reales de la cultura e historia nacionales, sin extrapolaciones o experimentos que producen "conflictos" en lugar de procesarlos y resolverlos, que ocasionan disonancia en lugar de concierto, así como un gran desperdicio de energía social colectiva y de fricciones innecesarias.

\section{CONSIDERACIONES GENERALES}

Ante las crisis constitucionales, ocasionadas tanto por los gobiernos divididos como por los de hiperconcentración en la rama ejecutiva, y la consecuente ingobernabilidad intermitente existente en México de 2000 a 2018, se han presentado una serie tanto de reformas como de propuestas de enmiendas constitucionales y políticas que parecen lógicas, a primera vista, y que últimamente han ido ganando adeptos, a pesar de que debilitan — desde nuestro punto de vista - a las instituciones, figuras jurídicas y disposiciones esenciales del constitucionalismo de 1917:

1. El original sistema presidencial mexicano.

2. El principio de sufragio efectivo y no reelección presidencial.

3. El articulado de contenido social del texto constitucional.

Ahora bien, no obstante lo anterior, un análisis serio, profundo y sistemático revela que dichas propuestas de reforma - en realidad una contrarreforma nociva para los mejores intereses de la República - constituyen un "espejismo" altamente peligroso, pues implican nada menos que el desmantelamiento total de la "coraza" o "blindaje" constitucional que brindaban al Estado mexicano: tanto el original sistema presidencial y el principio de 
la no reelección presidencial, como el articulado social - los originales artículos 27 y 123 constitucionales - plasmados en la Constitución de 1917, y que inyectaban vigor constante a la soberanía política, jurídica y financiera mexicanas.

Con base en todo lo anteriormente expresado, una de las premisas fundamentales de este ensayo será demostrar - a través de: 1) una visión retrospectiva del constitucionalismo mexicano; 2) una mayor precisión conceptual respecto a los términos de "constitución geográfica-demográfica" y "moral" y de la Constitución propiamente "política"; y 3) un análisis del lapso de las alternancias fallidas que van de 2000 a 2018 - que en realidad no es necesario implantar un sistema semipresidencial con gobierno de gabinete, ni establecer la reelección presidencial, así sea con una reducción del periodo presidencial actual de seis años a cuatro, como en el modelo estadounidense, ni mucho menos erradicar el contenido social que caracterizó y distinguió con un sello de prestigio a la Constitución de 1917; sino que, en todo caso, hay que restaurar el sentido original de la esencia del constitucionalismo de 1917, eso sí, con adecuaciones finas a la actual era de alternancia político-electoral y gran transformación nacional.

De otra forma, como se mostrará también lo largo de este ensayo, existe una serie de factores de tendencia globalizadora - provenientes del imperialismo trasnacional "trumpiano" y nacional - que vulnerará irremediablemente al Estado mexicano, convirtiendo a México en una nación nuevamente "maquiladora", dependiente, y sin capacidad de decisión de última instancia sobre el destino de sus riquezas humanas y naturales.

\section{RECONSIDERACIÓN DE LOS CONCEPTOS DE CONSTITUCIÓN GEOGRÁFICA-DEMOGRÁFICA Y MORAL, Y CONSTITUCIÓN POLÍTICA EN LA HISTORIA MEXICANA}

Por otro lado, es esencial — según se verá a lo largo de este ensayo - reexaminar y desempolvar los conceptos de "constitución geográfica", "moral" y "Constitución política", que nos serán extremadamente útiles para arrojar luces sobre aquellas propuestas constitucionales extraviadas que surgen de la desesperación académica de buena fe y del olvido de una realidad constitucional irrebatible que se nos presenta mediante las reflexiones que se harán en este ensayo.

Así pues, y recordando nuevamente, pero ya en detalle, las ideas de Esquivel Obregón, la palabra "constitución" se refiere a cómo está estructu- 
rado un ente, ya sea éste físico (individual) o moral (colectivo). En este sentido, por ejemplo, aplicando el término "constitución" a una persona, se dice que su constitución física es robusta, media o delgada, según sus características físicas particulares. ${ }^{8}$

Por otro lado, un país - entidad colectiva - que dispone de un territorio y una población determinadas tiene una "constitución geográfica-demográfica”, según sea su ubicación y su perfil demográfico en el globo terráqueo, variando dicha constitución geográfica-demográfica en términos de la presencia de montañas, valles y planicies, ríos y lagos, que conjuntamente con el clima y los recursos naturales de que dispone un territorio - y la población asentada en él - nos ofrecen un perfil histórico y psicológico colectivo único para cada país del mundo, lo que, como es natural, a su vez conduce casi irremediablemente a modelos variables de desarrollo comercial, económico y político que se consolidan en las fases iniciales de la historia de cada país. ${ }^{9}$ Así, por citar tan sólo un ejemplo sencillo y breve, las porciones no montañosas del territorio de los Estados Unidos de América - Kansas, Oklahoma, etc. - facilitaron enormemente el inicio y el desarrollo del comercio interestatal a través de la construcción de extensas líneas de ferrocarril, lo que a su vez estimuló la actividad económica y comercial que en otras regiones habría sido inicialmente incosteable por una configuración montañosa casi impenetrable. ${ }^{10}$

Así pues, la "Constitución" propiamente política de un país - para poder constituir ésta un texto realista, lógico y eficaz respecto al funcionamiento de sus instituciones fundamentales - debe de estar en armonía con la constitución propiamente geográfica-demográfica y hasta climatológica de dicho país, para poder alcanzar gradualmente la meta ansiada de una regulación eficaz, armónica y democrática de la vida política y electoral.

En el anterior sentido, es que afirmamos arriba que el texto constitucional de nuestra historia independiente que más se acerca al ideal de armonía entre "Constitución política” y "constitución geográfica-demográfica y climatológica", bajo el contexto de nuestro desarrollo histórico, es precisamente la carta magna de 1917, que no sólo respondió a urgentes reclamos momentáneos o de coyuntura, sino que desde nuestro punto de vista, respondió también a realidades psicológicas profundas de la idiosincrasia mexicana que siguen estando vigentes en el siglo XXI y que surgieron a

8 Cfr. Esquivel Obregón, Toribio, op. cit., pp. 13-15.

9 Idem.

10 Idem. 
flote en la crisis — no sólo constitucional sino armada - de la Revolución mexicana que nos enfrentó a los mexicanos con nuestro reflejo en el espejo de nuestras verdades más profundas en un momento único que, también afortunadamente, nos permitió encontrar las respuestas institucionales a nuestras verdades psicológicas más trascendentales.

Es por el motivo anterior, que creemos innecesario, e incluso en extremo arriesgado, abandonar la fórmula y las instituciones constitucionales esenciales que permitieron fortalecer gradualmente al Estado mexicano durante la mayor parte de los últimos 100 años, de frente a la actual crisis constitucional interna y ante el embate externo de afanes imperialistas y hegemónicos.

Por último, no podemos dejar de citar otro de los factores que en el lapso 2000-2018 ha precipitado la "desesperación académica" por buscar propuestas o soluciones ilógicas a nuestras crisis constitucionales tanto de gobierno dividido como de hiperconcentración de poder en la rama ejecutiva y falta de gobernabilidad, y que es la patética carencia de habilidades y destrezas políticas y jurídicas de la clase política gobernante. Dicha falta de preparación, experiencia y visión han profundizado y agudizado la multicitada crisis nacional, abonando el terreno de quienes proponen la adopción de un sistema semipresidencial con gobierno de gabinete y el abandono del principio de sufragio efectivo y no reelección presidencial, que cabe destacar es un principio casi sacrosanto para el presidente López Obrador que prometió - ante la nación entera en su discurso de toma de posesiónnunca desmantelar. En este sentido, la fortaleza intrínseca del contenido esencial de nuestro derecho constitucional — desde nuestro punto de vista - sólo requiere de modificaciones que trasladen de manera más fluida, lógica y sistémica el antiguo predominio del Ejecutivo a un nuevo esquema de "colaboración de poderes" que privilegie el papel protagónico que en el siglo XXI debe tener el Poder Legislativo mexicano complementado con un Poder Judicial realmente independiente, profesional y actualizado en los conocimientos de vanguardia jurídicos y constitucionales.

\section{El DiSEÑo CONSTITUCIONAL ORIGINAL DE LA CONSTITUCIÓN \\ DE 1917 Y SU CONTENIDO ESENCIAL: EL ORIGINAL SISTEMA PRESIDENCIAL, EL PRINCIPIO DE SUFRAGIO EFECTIVO Y NO REELECCIÓN,} Y EL ARTICULADO SOCIAL

Las crisis constitucionales que se han vivido en México de 2000 a 2018, y que nos han llevado frecuentemente a un gobierno dividido que obstaculiza la gobernabilidad democrática del país, han conducido — como ya adelan- 
tamos - a una suerte de desesperación académica bajo la cual han surgido propuestas - fruto de dicha desesperación - que no se encuentran adecuadamente fundamentadas en análisis y reflexiones jurídicas, políticas e históricas, que constituyen, desde nuestro punto de vista, el requisito sine qua non para descubrir que - irónicamente - la solución al impasse o crisis actual del constitucionalismo mexicano del siglo XXI está precisamente en el doble ejercicio de reflexión citado en el rubro anterior: Primero, en realizar una visión retrospectiva de nuestra historia constitucional, y en segundo término, en un análisis preciso, profundo y lingüístico del significado del término "constitución".

Así pues, el ejercicio de reingeniería constitucional mexicana que actualmente se encuentra extraviado en la búsqueda de esquemas ajenos a nuestra historia e identidad nacionales, como son el sistema semipresidencial con gobierno de gabinete o la potencial implementación de la reelección presidencial con una reducción del periodo presidencial de seis a cuatro años, o el desmantelamiento del articulado social de la Constitución de 1917, debe ser reorientado para lograr el "descubrimiento" de nuestra propia verdad profunda constitucional.

En este sentido, la mirada retrospectiva que - repetidamente hemos sugerido- es necesario realizar, nos indicará que a lo largo de nuestra historia han habido diversos intentos por encontrar la Constitución "política" adecuada a la constitución "física" geográfica, moral y social de México, y que algunos fracasaron - a veces parcial y a veces totalmente — según los esquemas de distribución de poder o de concentración ofensiva del mismo, como aconteció, por ejemplo, en el caso del llamado "Supremo Poder Conservador", contemplado en la segunda de Las Siete Leyes Constitucionales de 1836, y que estableció un constitucionalismo oligárquico, caracterizado fundamentalmente por el marcado carácter aristocratizante de sus disposiciones, así como por la naturaleza francamente disparatada de muchas de ellas.

De hecho, para algunos, la Constitución centralista contribuyó a acelerar la ruptura del pacto federal mexicano por Texas, pues los colonos angloamericanos de inclinación federalista habrían encontrado en Las Siete Leyes la mejor excusa para precipitar su independencia de México, lo que de todas formas hubiese ocurrido. La inestabilidad estuvo incluso a punto de provocar la separación de la Federación de la provincia de Yucatán, que incluía los estados actuales de Campeche, Quintana Roo y parte de Tabasco.

El texto centralista, denominado Las Siete Leyes Constitucionales de 1836, adoptó el modelo estadounidense del bicamarismo, sin embargo, el 
Senado tuvo una naturaleza sui generis dado que, al establecerse un gobierno de tipo centralista y desaparecer la organización federal, dejó de tener la representación de las entidades federativas. Por otro lado, tampoco era posible ubicar este Senado centralista como representante de los intereses de una clase social determinada — como en el caso de la Cámara de los Lores inglesa - porque estaba compuesto por individuos provenientes de la Cámara de Diputados, del gobierno en Junta de ministros y de la Suprema Corte de Justicia, elegidos indirectamente por las juntas departamentales.

Por otro lado, la tercera de las Leyes Constitucionales se dedicaba a la organización del Poder Legislativo. Los diputados serían electos por los ciudadanos en elección de segundo grado, y los senadores a través un procedimiento especial. Para ser diputado o senador se exigían curiosos requisitos, entre otros, tener una renta mínima de 1500 pesos al año para ser diputado, y de 2500 pesos al año para ser senador. Es decir, esta Constitución fue descaradamente aristocrática, pues sólo las personas con capacidad económica podían ocupar puestos de representación, lo que aún en la época era un verdadero dislate.

Por último, la ya citada segunda de dichas Leyes Constitucionales se ocupó de la división de los poderes. Contempló los tres clásicos, Legislativo, Ejecutivo y Judicial, y además creo uno nuevo, llamado "Supremo Poder Conservador", la característica distintiva de la Constitución de 1836. El Supremo Poder Conservador se integraba con cinco miembros, y cada dos años se sustituía a uno. Para ser miembro, se requería una edad mínima de 40 años, una renta anual mínima de 3000 pesos, y haber sido presidente de la República, vicepresidente, ministro de la Suprema Corte, gobernador o senador. En pocas palabras, una elite extraordinariamente reducida podría cumplir con los requisitos para integrar el Supremo Poder Conservador, cuyas facultades eran amplísimas, casi absolutas. Recordemos que las facultades más importantes del Supremo Poder Conservador eran desconocer los actos de los tres poderes, desconocer a los tres poderes y reformar la Constitución.

Del anterior interludio histórico que usamos como "botón de muestra" es fácil percatarse de los riesgos y peligros que se derivan del rediseño equivocado, frívolo o superficial de los pilares del constitucionalismo de un país determinado.

En el anterior sentido, y en referencia a la concentración del poder político, cabe destacar que, en la actualidad, la figura de los coordinadores estatales de programas de desarrollo que propone AMLO ha generado críticas 
de algunos gobernadores, ${ }^{11}$ quienes expresan preocupaciones por esta nueva posición que el presidente constitucional AMLO ha defendido, asegurando que se trata de una facultad del Poder Ejecutivo para reducir el gasto y no para interferir en la soberanía de los estados, como según alegan algunos gobernadores y analistas que equiparan la figura de los coordinadores estatales a una especie de virrey del siglo XXI, ${ }^{12}$ aunque AMLO ha declarado que su única función será "certificar que los recursos federales lleguen, íntegros y sin intermediarios, a los gobiernos de los estados y que se gasten de manera correcta para cumplir con los programas y con las obras para las que fueron asignados". ${ }^{13}$

Por otro lado, las propuestas de desmantelar el sistema presidencial original, el principio de no reelección presidencial y el articulado social de la Constitución mexicana, constituyen, potencialmente, un yerro de dimensiones similares a las disposiciones descabelladas contenidas en la Constitución centralista de 1836, porque se piensa que con el establecimiento de un sistema semipresidencial con gobierno de gabinete - colectivización de decisiones - se estará a salvo de autoritarismos, gobiernos divididos o toma de decisiones deficientes.

En resumen, no fue sino hasta 1917, cuando podríamos decir que surge una Constitución Política que no sólo correspondió aceptablemente a la realidad del momento mexicano en la que se gestó, sino que plasmó en un proyecto de nación — realizable gradualmente- los afanes y aspiraciones más urgentes y profundos de la nación mexicana.

De manera sintética podemos observar que el texto constitucional de 1917 fue el resultado:

1. De acuerdos plurales.

2. De una lucha armada genuina, legítima y fundada en un reclamo social impostergable que convulsionó al país.

3. Creó una normatividad sui generis que respondía a las exigencias de las mayorías, surgiendo así la primera Constitución de naturaleza

11 Ramírez, Julio, "Los coordinadores estatales de AMLO generan incertidumbre entre gobernadores", Expansión Política, México, 2 de agosto de 2018, disponible en https://po litica.expansion.mx/presidencia/2018/08/02/los-coordinadores-estatales-de-amlo-generanincertidumbre-entre-gobernadores.

12 Ajenjo, Manuel, “¿Coordinadores estatales o virreyes?”, El Economista, México, 15 de agosto de 2018, disponible en https://www.eleconomista.com.mx/opinion/Coordinadoresestatales-o-virreyes-20180815-0135.html.

13 Idem. 
social con un proyecto nacional incluido en su articulado, que nació de un proceso de ingeniería constitucional inteligente y realista que tomó en cuenta factores geográficos, étnicos, morales, psicológicos y forjó tradiciones nacionales, alejándose de las imitaciones extralógicas.

Así pues, deben evitarse en los procesos de reingeniería constitucional nacionales - como que el que actualmente parece gestarse en México- los procesos de extrapolación e imitación artificial de instituciones extranjeras que surgieron en otras latitudes, precisamente dando respuesta a reclamos y condiciones propias de otros países y naciones. En este sentido, abandonar el original sistema presidencial mexicano y el principio de no reelección presidencial, así como el articulado constitucional de contenido social, constituye desde nuestro punto de vista un proceso equivocado surgido de una precipitación innecesaria que podría conducirnos a mayores y más peligrosas crisis constitucionales y políticas de las que hasta ahora hemos presenciado.

Por todo lo anteriormente expresado, las propuestas actuales: sistema semipresidencial con gobierno de gabinete y el "coqueteo" con el establecimiento de una reelección presidencial, así sea combinada con la reducción del periodo actual de seis a cuatro años, equivocan el rumbo, ya que el verdadero problema que conduce a la actual crisis constitucional mexicana surge debido a que el espíritu original del sistema presidencial mexicano, del principio de no reelección referido y del articulado social de la carta magna, se ha ido adulterando -inicialmente de manera casi imperceptible, y en las últimas dos décadas de manera acelerada - lo que nos ha conducido precisamente a un desfase entre el diseño del andamiaje constitucional y la realidad política nacional, desfase que puede ser corregido y afinado mediante modificaciones y reformas que no requieren de alteraciones sustanciales de sistemas de gobierno o de principios útiles a la idiosincrasia política mexicana o del desmantelamiento de las instituciones sociales que constituyen la nota característica de nuestro constitucionalismo.

Por lo tanto, para describir el fenómeno de desfasamiento arriba citado, podríamos - mediante una descripción teórica - señalar que se ha dado una serie de efectos distorsionadores del sistema presidencial mexicano clásico en distintas fases características del sistema político y constitucional de México: 
1. El predominio o hegemonía del Poder Ejecutivo respecto al Legislativo y Judicial, que desde la era posrevolucionaria y durante las décadas posteriores constituyó una necesidad histórica.

2. La prolongación artificial del presidencialismo hegemónico mexicano - más allá de su lapso de funcionamiento natural — probablemente a partir de 1968, inhibió el desarrollo, crecimiento y fortalecimiento del Poder Legislativo federal, y mantuvo "sumiso" al Judicial.

3. La citada prolongación artificial del modelo original finalmente hace crisis en el lapso de las alternancias fallidas - 2000 a 2018 - en el cual opera en una suerte de "vacío" con un andamiaje institucional que no es el original, que carece de las modificaciones necesarias para ser funcional, eficaz y democrático, y que aunque formalmente se caracteriza por contar con los elementos del modelo original, es inoperante debido a las carencias personales y colectivas de la clase política gobernante, todo lo cual lo convierte en la realidad actual en un andamiaje aparentemente obsoleto e ineficaz.

La solución al anterior panorama de crisis constitucional de gobiernos divididos o bien de hiperconcentración de poder en la rama ejecutiva - que impide la gobernabilidad - está en reflexionar sobre las condiciones anteriormente analizadas, someterlas a crítica y realizar propuestas de reforma estructural a través del doble ejercicio ya sugerido de la retrospectiva histórica y de la reconceptualización de los términos de Constitución "política" y constitución propiamente "geográfico-demográfica" y moral.

\section{LOS FACTORES GEOPOLÍTICOS MUNDIALES QUE VULNERAN LA SOBERANÍA POLÍTICA, JURÍDICA Y FINANCIERA DE LA NACIÓN MEXICANA, VÍA LAS PROPUESTAS DE CONTRARREFORMA DE LOS TRES PILARES DEL CONSTITUCIONALISMO NACIONALISTA Y SOCIAL DE 1917}

Como parte esencial de este ensayo, se encuentra el rubro referente a los factores geopolíticos mundiales contemporáneos que inciden en la necesidad de salvaguardar la soberanía política, jurídica y financiera económica de México, una vez restaurado, mejorado y actualizado el modelo presidencial mexicano clásico y reafirmado el valor vigente del principio de la no reelección presidencial y del articulado de contenido social de la carta magna de 1917, con las modificaciones que se propondrán, y que evitarán crisis consti- 
tucionales y quizá incluso militares de mayor peligrosidad para la República mexicana.

En este sentido, se hará referencia a un listado de factores que en la actualidad están en juego y operando para promover (los primeros tres) o detener (el cuarto factor) el debilitamiento del Estado mexicano:

1. El proyecto neoliberal de los Estados Unidos de América, el intento de restauración de la presidencia imperial estadounidense de Trump y la estrategia globalizadora.

2. La mundialización financiera, económica y jurídica.

3. Los recursos naturales mexicanos como botín y objetivo fundamental de intereses trasnacionales, y que durante la mayor parte del siglo XX estuvieron bajo control y dominio del Estado mexicano surgido de la Revolución de 1910.

4. La Constitución de 1917 como valladar efectivo ante el embate hegemónico extranjero, con base en los tres pilares del original sistema presidencial, el principio de no reelección presidencial, y el articulado de contenido social.

Resumiendo, cabe decir que el sistema presidencial clásico mexicano permitió contar — en la mayoría de las administraciones, y en especial en momentos críticos como el del sexenio del general Lázaro Cárdenas- con estadistas altamente inteligentes, preparados y visionarios que supieron encontrar las fórmulas políticas y jurídicas para mantener incólume la soberanía nacional sobre nuestro territorio, políticas, sistema jurídico y recursos naturales.

Por otro lado, el principio de la no reelección presidencial que permitió el reciclaje e inyección de sangre nueva en las elites políticas, evitaba también — en combinación con el Poder Ejecutivo hegemónico - una injerencia perversa de cabilderos nacionales o extranjeros en la confección de leyes o políticas legislativas que en la actualidad parecen haber quedado a merced de oligopolios nacionales o transnacionales - como en el caso Odebrecht ${ }^{14}$ en México-, que abogan por la abolición del principio de la no reelección presidencial para facilitar su labor de "compra de voluntades" y de determinación de la agenda política nacional.

14 "El caso Odebrecht sacude a México por acusaciones contra el exdirector de la petrolera estatal", The New York Times en español, 2017, disponible en https://www.nytimes.com/ es/2017/08/15/odebrecht-mexico-emilio-lozoya-pemex-corrupcion/. 
Por último, el articulado de contenido social (artículos 27 y 123 constitucionales) — como tercer pilar del constitucionalismo mexicano- buscó la construcción y consolidación de instituciones y tradiciones en el ámbito rural, agrario, campesino y en el sector laboral, para evitar la incursión inconveniente de intereses comerciales nacionales o extranjeros que en etapas previas de nuestra historia habían sojuzgado a las clases campesina y trabajadora, hasta llegar a las condiciones de opresión e injusticia que condujeron al movimiento armado de $1910 \mathrm{y}$, como ya hemos afirmado repetidamente, a la consagración constitucional en el texto de 1917 de las instituciones, principios y figuras jurídicas de una Constitución Política que respondía a los intereses, necesidades y realidades más profundas del ser mexicano.

\section{CONSIDERACIONES FINALES}

En los últimos 30 años en México se ha presenciado una dinámica de confrontación tanto política como académica entre quienes proponen el establecimiento en nuestro país - de manera irreversible y consolidada - de un Estado neoliberal cuyas dos características distintivas principales han sido la libre entrada del imperialismo trasnacional, y la operación sin valladares y obstáculos internos de las oligarquías y oligopolios nacionales teniendo como contrapartida a quienes apoyan la conservación de un Estado mexicano nacionalista y fuerte anclado ${ }^{15}$ en sus instituciones pilares, plasmadas y consagradas precisamente en la Constitución de 1917 a través del original sistema presidencial, el principio de la no reelección presidencial y el articulado de contenido social. En este sentido, quienes promovieron el Estado neoliberal, en realidad buscaban implementar una contrarreforma política $y$ jurídico constitucional expresada en:

1. Un cambio a un sistema semipresidencial con gobierno de gabinete.

2. La modificación del principio de la no reelección presidencial.

3. La apertura indiscriminada del sector energético.

4. La apertura de la explotación y comercialización rapaz de los recursos naturales e hidráulicos.

15 "Discurso íntegro de Andrés Manuel López Obrador al rendir protesta como presidente", Animal Político, México, 1 de diciembre de 2018, disponible en https://www.animalpo litico.com/2018/12/discurso-integro-amlo-protesta-presidente/. 
5. El establecimiento de un marco normativo en materia de cabildeo favorable a la globalización trasnacional.

6. La profundización de la debilidad actual del Estado mexicano sin el vigor de los principios jurídicos fundamentales de la Constitución de 1917.

7. La importancia crucial de la alteración del equilibrio de poderes entre el Ejecutivo y el Legislativo.

8. El surgimiento de los medios de comunicación masiva como oligopolio económico que superaba al oligopolio político de los partidos, antes dominante, y que fue esquivado por AMLO en su campaña de ascenso a la presidencia de la República a través de las redes sociales.

Ahora bien, para contrarrestar el escenario anterior de naufragio o desastre nacional, es indispensable (y este ensayo se inscribe en esta corriente):

1. Desempolvar y restaurar el significado profundo y original de los tres multicitados pilares del Estado mexicano plasmados en el texto constitucional de 1917.

2. Establecer una conceptualización precisa y profunda de la trascendencia que tienen los términos de constitución "geográfica-demográfica" y moral y Constitución propiamente "política" como fundamentación teórica y práctica del porqué es necesario revalorizar y rescatar el andamiaje esencial del constitucionalismo de 1917.

3. Analizar con seriedad el concepto de "constitución moral" como útil - a pesar de las críticas de analistas que han "frivolizado" dicho concepto- pues, ante la devastación ética actualmente existente en México, nos parece en realidad el elemento restante para configurar una tripleta de conceptos (a) Constitución política, b) constitución geográfica, racial y psicológica y c) constitución moral), útil en la labor de "reingeniería" para la interpretación profunda de la Constitución original de 1917. 